\title{
Differential interformational velocity analysis as an effective direct hydrocarbon indicator under velocity reversal conditions, an example from the anomalously high temperature and over-pressured DF1-1 Gas Field in the Yinggehai Basin, South China Sea
}

\author{
Zhu Hongtao ${ }^{1,2 *}$, Liu Keyu ${ }^{2}$, Chen Kaiyuan ${ }^{3}$, Li Min ${ }^{1}$ and Huang Shengbing ${ }^{1}$ \\ ${ }^{1}$ Key Laboratory of Tectonics and Petroleum Resources of the Ministry of Education, China University of Geosciences, \\ Wuhan, Hubei 430074, China \\ ${ }^{2}$ CSIRO Petroleum, P. O. Box 1130, Bentley, WA 6102, Australia \\ ${ }^{3}$ School of Energy Resources, China University of Geosciences, Beijing 100083, China
}

\begin{abstract}
In the DF1-1 Gas Field in the Yinggehai Basin, South China Sea, the velocity-depth plot and velocity spectra show significant variations from a linear trend, exhibiting a distinct reversal phenomenon. Velocity parameters derived from velocity spectral analysis of the seismic data and sonic logs indicate that the interval velocity reverses below 2,100 m (2.2 s two-way time (TWT)) in the DF1-1 Gas Field. Some direct hydrocarbon indicators (DHIs) models developed for the shallow strata cannot be simply applied to the moderately to deeply buried strata for direct exploration target recognition because the velocity reversal has caused the middle-deep gas reservoirs to exhibit a moderate or weak seismic amplitude. The hydrocarbon indicator method of "Differential Interformational Velocity Analysis (DIVA)" with the aid of other hydrocarbon indicating techniques was employed to effectively identify DHIs in the middle-deep strata under velocity inversion. The result has shown that the DIVA technique can be effectively used as a DHI in both the shallow and the middle-deep strata in the study area with the shallow strata characterized by Type I DIVA anomaly and the middle-deep strata characterized by the Type II DIVA anomaly.
\end{abstract}

Key words: DF1-1 Gas Field, velocity reversal, direct hydrocarbon indicator, differential interformational velocity analysis, South China Sea

\section{Introduction}

Seismic velocity is an important parameter in petroleum exploration and can be used to derive Direct Hydrocarbon Indicators (DHIs). Velocity data from well logs become a vital tool to (1) differentiate lithologies, (2) determine facies and reservoir attributes, (3) deduce fluid types and detect overpressure regimes, (4) obtain information about the burial and thermal history, and (5) generate synthetic sections for the effective interpretation of seismic data.

Normally, the relationship between the acoustic velocity of sedimentary rocks and their burial depth is linear. Such a relationship is often used to estimate sediment composition, porosities, pore-pressures, burial history, and compaction processes (He et al, 2002). However, Storvoll et al (2005) used $\log$ data from 60 wells on the Norwegian Shelf to investigate the velocity-depth trends in sedimentary rocks. They found that most of the velocity variations did not follow

*Corresponding author. email: zhuht_oscar@yahoo.com.cn Received January 12, 2009 a linear velocity-depth trend and concluded that "no general velocity-depth function can be used when performing more accurate analyses like depth conversion of seismic data, pore-pressure prediction, or basin modeling". Japsen (2006), however, believed that there existed a general velocity-depth function that could be used for various analyses. Therefore, it has been a subject of heated debate on whether one can come up with a general velocity-depth function for sedimentary rocks. So far there is no general consensus reached on this issue.

The bright spot technique, an important seismically derived DHI method, has been successfully applied in delineating hydrocarbon reservoirs seismically in some parts of the world (Yin et al, 2003; Young and Tatham, 2007). However, this method appears to be only effective for identifying the shallow gas reservoirs (above 2,100 m), in the Yinggehai Basin, South China Sea (Li, 2000). Below 2,100 $\mathrm{m}$, the bright spot technique becomes ineffective. In fact in the Yinggehai Basin, some bright spots do not appear to indicate oil or gas accumulations in the middle-deep strata at all (Li, 2000). It is thus necessary to investigate whether this 
technique can be applied in the region. Because the bright spots are mainly controlled by the velocity parameters, it is essential to understand how the velocity changes in the Yinggehai Basin under the special geological settings of high temperature, high pressure, and moderately to deeply buried strata. The sensitivity and limitations of the bright spot technique in deeper strata in general need to be further evaluated. The effects of seismic velocity characteristics on exploration target delineation and the corresponding measures require vigorous investigation in order to provide insight for future exploration of the middle-deep oil and gas reservoirs in this basin.

The Differential Interformational Velocity Analysis (DIVA) technique using ultra refined seismic velocity analysis has been developed to identify and delineate low velocity anomalies in the subsurface. Porous reservoir rock formations can be distinguished by their reduced seismic velocities regardless of whether hydrocarbons are present. Where gas is present, the velocity reduction can be significant which makes the DIVA anomaly an excellent indicator with much visual impact compared to the bright spot technique. The DIVA technique has not only been proven by drilling but also been used to define unconventional exploration plays which cannot be detected using conventional seismic parameters (Cook et al, 1983).

Although velocity reversal has been recognized in the Norwegian Shelf by Storvoll et al (2005), its impacts on the DHI have not been discussed in any detail. The aim of this study is to understand the velocity-depth relationship of the study area based on the velocity data from sonic logs and seismic data. Published data showed that the velocity- depth trend in the Yinggehai Basin is non-linear; instead, the interval velocity exhibits reversal below $2.2 \mathrm{~s}$ (or 2,100 m). This study also aims to test and evaluate the hydrocarbon indicator method of DIVA that may be applied effectively under velocity reversal conditions, so as to help reduce the risks associated with future exploration in this area.

\section{Geological setting}

The Yinggehai Basin, which is located southeast of Hainan Island and has a NW-SE orientation, is a relatively young, gas-rich, Cenozoic extensional and super-pressured basin in the South China Sea (Fig. 1). This basin is filled with up to $18 \mathrm{~km}$ of Tertiary clastic sediments on the Paleozoic and Mesozoic basement rocks (Huang et al, 2003). The complete stratigraphic sequence has not been drilled through (Yuan et al, 2009; Zhou and Yao, 2009). The structural evolution of the Yinggehai Basin can be divided into two major stages: an Eocene-Oligocene syn-rift sequence and a post-rift thermal subsidence sequence.

The Yinggehai Basin has recently been studied extensively because it is the major hydrocarbon producing basin in the South China Sea, and has many unique geological features including: 1) high subsidence and deposition rates with the maximum sedimentation rate up to $1.2 \mathrm{~mm} / \mathrm{yr}$ (Huang et al, 2005; Zhang et al, 2008; Yan et al, 2009), 2) high geothermal gradients varying from 3.1 to $4.56{ }^{\circ} \mathrm{C} / 100 \mathrm{~m}$ (He et al, 2002; Huang et al, 2003), 3) high heat flow ranging from 69 to 86 $\mathrm{mW} / \mathrm{m}^{2}$ with a mean value of $79 \pm 7 \mathrm{~mW} / \mathrm{m}^{2}$ (He et al, 2002), 4) abnormally high overpressure with the pressure coefficient up to 2.3 (Hao et al, 2000; Huang et al, 2003), and 5) the



Fig. 1 Map showing the location of the DF1-1 Gas Field in the Yinggehai Basin 
presence of regional diapir activities (Xia et al, 2006).

The DF1-1 Gas Field, first discovered in 1992, is located in the northern part of the Yinggehai Basin. The field contains estimated gas resources of over $1,000 \times 10^{8} \mathrm{~m}^{3}$ consisting mainly of hydrocarbon gas, $\mathrm{N}_{2}$, and $\mathrm{CO}_{2}$ (Hao et al, 2000).

The main source rocks are in the Miocene Huangliu, Meishan, and Sanya formations comprising calcareous shales, grey sandy limestones and grey biogenic limestones interbedded with grey and dark grey mudstones, light grey siltstones and fine sandstones. The overlying HuangliuYinggehai formations and the Quaternary sediments consist of sandstones and shales, forming several sets of reservoirseal pairs. Shale diapir structures have developed in the central depression of the Yinggehai Basin (Fig. 1).

\section{Velocity characteristics}

The sonic velocity data from the wells in the DF1-1 Gas Field are shown in Fig. 2. These are plotted separately for different lithologies and gas-bearing intervals so as to better illustrate the variations. Compared with the estimated trend line of the published data (red dash-line), the velocity-depth plot of the field exhibits two intervals with different trends ("A" and "B" in Fig. 2). Detailed information of the published sonic velocity data in Fig. 2 include: 1) the sonic velocity of nine shaly units of Oligocene to early Cretaceous age from 81 wells located in the North Sea (Teige et al, 1999), 2) velocity data of the Garn sandstone and the Not and Ror shales from the further 28 wells located offshore mid-Norway (Hermanrud et al, 1998), and 3) velocity data of normally compacted shales from 32 wells in the North Sea and Norwegian Sea (Hansen, 1996).

Interval "A" (Fig. 2) shows a good linear velocitydepth trend when excluding the data from the gas-bearing sandstones. However, the slope of the trend line shows a higher velocity-depth gradient compared with the published data listed above. Interval "A" consists mainly of the Yinggehai Formation, which is made up of argillaceous silty sandstone, fine sandstone, siltstone, and mudstone. Furthermore, there are distinct variations between the gasbearing sandstones and the surrounding rocks from 1,250 to $1,500 \mathrm{~m}$ in the shallow stratigraphic section. Combined with drilling and seismic data, it is demonstrated that the seismic compressional wave $(\mathrm{P})$ velocity of the gas-bearing sandstones above $2,000 \mathrm{~m}$ is $30 \%$ or more lower than that of surrounding mudstone rocks ( $\mathrm{Li}, 2000)$.

Interval "B" shows the velocity data from the Meishan to Yinggehai formations. The sediments are similar to those of interval " $\mathrm{A}$ " except for the presence of argillaceous fine siltstone. The velocity data of interval "B" do not show a classical linear velocity-depth trend, instead exhibiting a reversal compared with the published data below 2,100 m. Moreover, the difference between the gas-bearing sandstones and the surrounding rocks below 2,100 $\mathrm{m}$ in the middle-deep stratigraphic sections is not apparent.

Fig. 3 shows the velocity spectral data derived from the seismic data in the study area including interval velocity (a) and a single velocity spectrum at common depth point (CDP)



Fig. 2 Sonic velocity data derived from well logs above the Meishan Formation, DF1-1 Gas Field. The velocities of different lithofacies are plotted in different colors and legends to better illustrate the variations. The dashed line shows the classical linear trend; solid lines show the real trends 
2,400 (b). In the interval velocity section (Fig. 3(a)), the measured seismic velocity of each CDP increases gradually until about $2.25 \mathrm{~s}$. Below this depth, it exhibits a distinct velocity reversal as indicated by the velocity map (Fig. 3(a)). Different CDPs appear to have different velocity reversal depths. On the single velocity spectrum of CDP 2,400 (the left part of Fig. 3(b)), the stacked velocity still shows a linear velocity-depth trend until 2.25 s. It shows a subvertical velocity-depth trend down to $2,520 \mathrm{~m} / \mathrm{s}$. The interval velocities of CDP 2,400 (the right part of Fig. 3(b)) are similar to the velocity data from wells, with a linear velocitydepth trend until $2.25 \mathrm{~s}$ but exhibiting reversal below $2.25 \mathrm{~s}$.

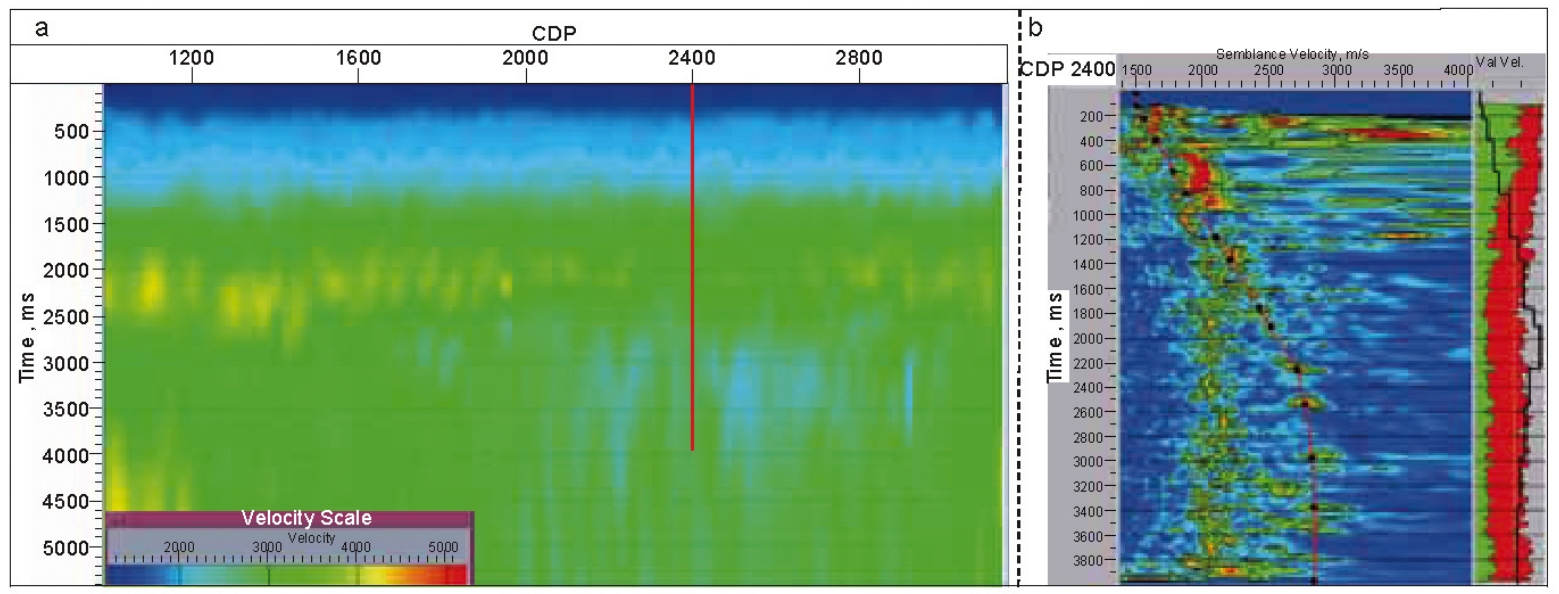

Fig. 3 Interval velocity characteristic sections derived from velocity spectral analysis of a representative seismic line in the DF1-1 Gas Field. The left (a) is the interval velocity section (see Fig. 1 for the location of line), and the right (b) is the single velocity spectrum at CDP 2,400 with position shown as red line in the left (a)

Fig. 4 displays the density variations with depths from well logs above the Meishan Formation in the DF1-1 Gas Field. They are similar to the trends of their velocity-depth plot with a normal linear density-depth trend until 2,100 m below which they exhibit reversal.



Fig. 4 Log-derived density-depth plots above the Meishan Formation, DF1-1 Gas Field. The data are plotted in different symbols to better illustrate the variations

\section{Factors affecting velocity anomalies}

The main factors affecting velocity are believed to be: 1) fluid density, 2) matrix density, 3) water saturation,
4) porosity, 5) effective pressure (both pore pressure and overburden pressure), 6) rock composition (mainly shale content), 7) granularity, 8) cementation, 9) temperature, and 10) age/depth (Storvoll and Bjørlykke, 2004). We believe that the dominant factors that influence velocities need to be determined for each individual area under different conditions. We do not intend to discuss the controlling factors that cause the velocity anomalies in details, but concentrate on how the velocity anomalies affecting DHIs.

The Yinggehai Basin is presently under high temperature and abnormally high pressure conditions. For example, the DF1-1-11 well with a total depth (TD) of 3,508 $\mathrm{m}$ has a maximum borehole temperature of $167.85^{\circ} \mathrm{C}$ compared with a borehole temperature of $107.84{ }^{\circ} \mathrm{C}$ at $2,100 \mathrm{~m}$, has a maximum pressure of more than $70 \mathrm{MPa}$, and has a pressure coefficient of 2.18. Fig. 5 shows the measured and estimated pressure coefficient distributions, in which the pressure coefficient increases abruptly below 2,100 m. Although pressure estimations from mud weights give a rough estimate of maximum pore pressure in the well, they still can be thought of as a reference to indicate underground pore pressure. Through analyzing the measured velocity data of sandstones and mudstones of the DF1-1-11 well, the starting depth of velocity reversal is determined at approximately $2,100 \mathrm{~m}$, which corresponds to the overpressure depth. Detailed analysis of the lithostratigraphic column of DF1-111 well indicates that the velocity reversal does not correlate with any significant lithological changes. 


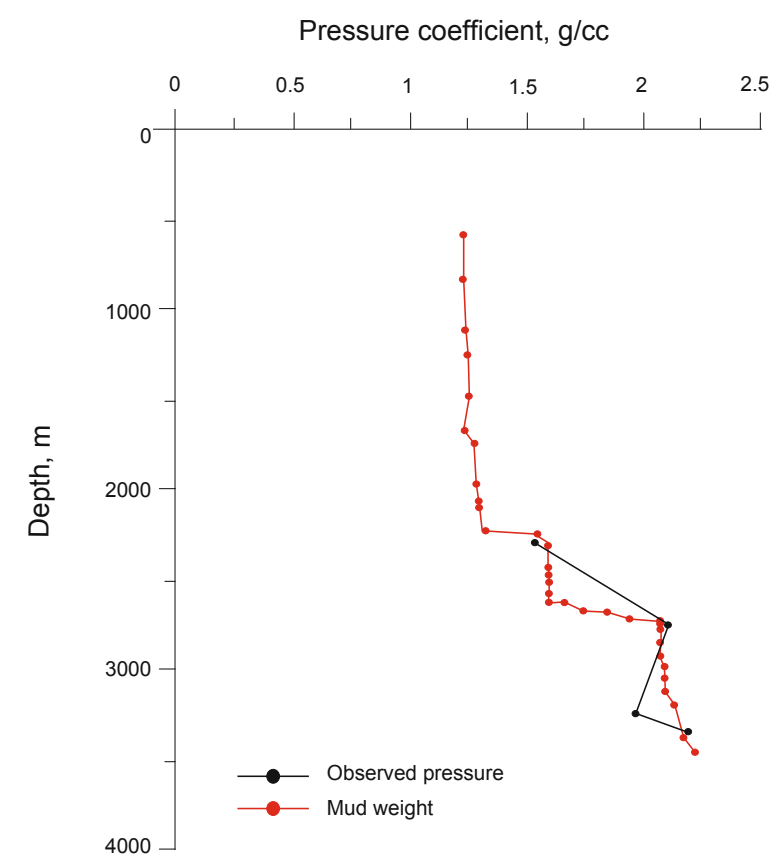

Fig. 5 Observed pressure and mud weight curves of the DF1-1-11 well

The velocity reversal phenomenon appears to be controlled mainly by the factors of high temperature and high pressure. Because of the high subsidence and sedimentation rates of the basin, sediments were generally under-compacted with large amounts of fluids trapped in the sediments, which led to super-pressure that decreased velocity and caused velocity reversal. Such a phenomenon is more obvious if oil and gas, especially natural gas, is present. Rocks bearing a large amount of un-discharged fluids may cause abnormally low velocity. The phenomenon appears in both undercompacted mudstones and sandstone reservoirs because of the presence of abundant natural gas (Fig. 2).

\section{Effects of velocity characteristics on exploration target delineation}

Velocity is an important parameter that has been routinely used to derive DHIs. The velocity reversal in the middledeep strata in the DF1-1 Gas Field of the Yinggehai Basin has caused much unsatisfactory interpretation or complete failure of the velocity-derived DHI techniques.

In the shallow section of the Yinggehai Basin, the reflection of the shallow gas reservoirs is characterized by strong amplitude anomalies (bright spots) on seismic profiles (Fig. 6) because of the pronounced acoustic impedance difference between the gas-bearing strata and the overlying or underlying strata, and is characterized by Type III AVO (Amplitude Versus Offset) anomaly whose amplitude increases with offset on CDP gathers (Fig. 6) (Loizou et al, 2008). The acoustic impedance is controlled by the velocity and density of the strata. Because the velocity and density of gas-bearing strata in the study area are both significantly lower than those of the surrounding rocks (Figs. 2 and $5)$, there is a strong acoustic impedance difference with pronounced bright spots shown on the shallow seismic profiles in the study area. However, in the middle-deep strata, the gas reservoirs appear to have a different reflection mode and usually display a moderate or weak amplitude. This does not allow the development of strong acoustic impedance difference (bright spots) because the reversal of both the velocity and density causes the ambiguity between the gasbearing sandstones and the surrounding rocks.

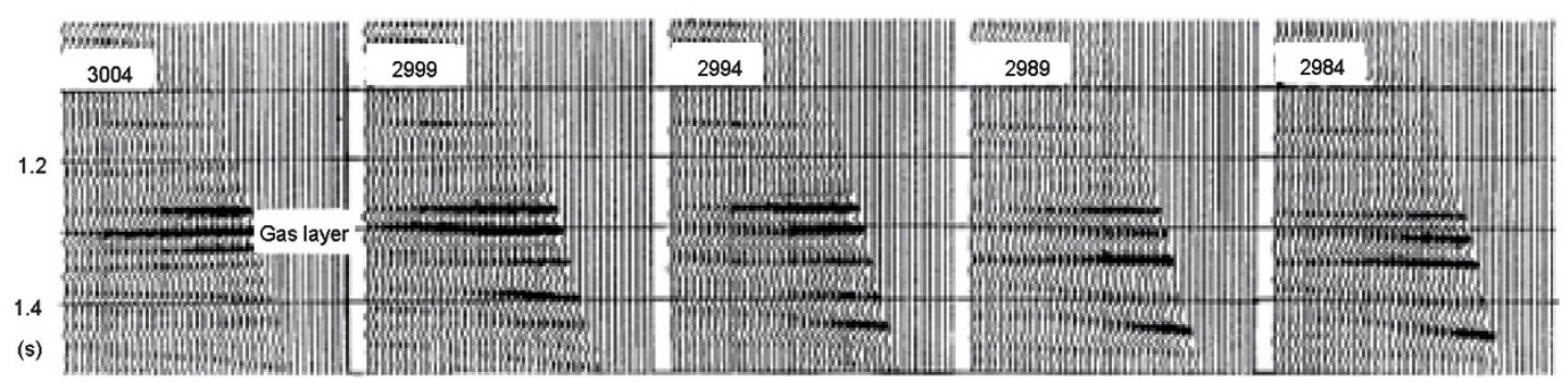

Fig. 6 Reflective characteristics of gas-bearing sandstones, showing high acoustic impedance difference and high amplitude and bright spots reflection between gas-bearing sandstones and the surrounding rocks in the shallow strata of the study area

Velocity reversal can cause the bright spot technique to be ineffective in the middle-deep strata. It often shows faded spots or dark spots on the seismic profile in the middle-deep strata of the Yinggehai Basin. Therefore, the exploration model developed from the shallow gas reservoirs cannot be directly applied to the deep reservoirs. Three types of bright spots were previously recognized by Li (2000) in the Yinggehai Basin, including 1) low-velocity type, 2) density type, and 3) calcium type. When using the bright spot technique, it must be noticed that non-gas-bearing sandstones can cause "fake bright spots" on the deep seismic sections. The "fake bright spots" mentioned above may be the latter two types of $\mathrm{Li}$ (2000). The "true" gas-bearing bright spots become dark spots or flat spots due to the changes of special physical and geological conditions, such as high temperature, overpressure, and the degree of rock consolidation. It can be misleading and lead to exploration failures if we only rely on the bright spots as the DHI techniques for exploring hydrocarbon reservoirs in deeper strata.

It is therefore important to detect some bright spots or 
other characteristic hydrocarbon indicators on the seismic profiles in the middle or deep strata of the Yinggehai Basin. If the bright spot technique is to be used, one should pay great attention to searching for the "phase reversal" and "dark spots". Alternatively one may use other hydrocarbon indicating techniques to detect hydrocarbons from the characteristics of the seismic profiles, such as 1) Jason inversion using seismic and well-log data; 2) AVO attribute parameter cross-plot including Gradient Versus Intercept, Gradient Versus Fluid Factor, and Gradient Versus Poisson Ratio; 3) DIVA; and 4) high-order statistics to detect other hydrocarbon indicators of the seismic expression in middle or deep strata. Some of the techniques have been put into practice in stratigraphic gas exploration in the Yinggehai Basin, resulting in successive discoveries of several medium to small gas fields.

\section{Application of the DIVA technique}

The DIVA, a useful seismic technique, which makes use of ultra refined seismic velocity analysis, has been developed to identify and localize low velocity anomalies in the subsurface (Cook et al, 1983). The DIVA technique has been shown to be an effective hydrocarbon indicating technique and has been applied successfully in some parts of the world, especially in some terrigenous basins (Zhu et al, 2004). However, there are no publications that directly address the DIVA method with regard to the velocity reversal issue. Therefore, it is essential to evaluate whether this technique can be successfully applied in the Yinggehai Basin, South China Sea.

\subsection{Experimental method}

The DIVA procedure consists of four steps:

1) Plot the velocity data by using the interval velocity data from the pre-stack seismic data with the velocity as $y$-axis and CDPs as $x$-axis;

2) Assemble the DIVA curves by using the first shallow velocity curve to assemble the next (deep) curve sequentially until the last curve; use the second shallow velocity curve to repeat above-mentioned step until the second last to final curves with the shallow curves marked as solid lines and the deep ones as broken lines;

3) Arrange the DIVA sections by using the DIVA curves assembled in step 2) to generate the DIVA sections according to the order of sequence from shallow to deep;

4) Rank and interpret the DIVA sections.

When the deep velocity is lower than the shallow one, it would show a velocity abnormal area that can be used to evaluate and ascertain the potential gas-bearing zones based on the reliability of velocity anomalies shown on the DIVA sections. The DIVA abnormal classes are usually marked with Roman numerals on the DIVA sections with class I being the best potential zone while class IV being the worst. Each Roman number has a numerical footnote representing the serial number grades of abnormal zones with the smaller ones being the better in the same class.

\subsection{Experimental results}

For the evaluation and application of the DIVA technique in the middle-deep strata of the line in the DF1-1 Gas Field, one seismic section (Fig. 1) was selected. We compared it with the DIVA sections derived from the shallow, middle, and deep strata to evaluate the effectiveness of DIVA as a DHI in the deep strata of the Yinggehai Basin. In this test, the shallow objective is named as "a" segment, the middle objective as "b", the deep objective as "c", each of which comprises about 10 reflecting interfaces beginning from numeral 1 from shallow to deep strata.

Table 1 lists the velocity analysis interface parameters illustrated in three DIVA sections on the seismic line (Figs. 7-9), where the "a" segment between $\mathrm{T}_{27}$ and $\mathrm{T}_{29}$ (see Fig. 1 for location) reflecting interfaces is the main gas-bearing strata, made up of 10 reflecting interfaces in the DF1-1 Gas Field.

Table 1 Velocity analysis interface parameters of target intervals using DIVA in the DF1-1 Gas Field

\begin{tabular}{cccccc}
\hline Target zone & TWT, $\mathrm{s}$ & CDP range & Layer range & Layer attribute & Remarks \\
\hline $\mathrm{a}_{1}-\mathrm{a}_{10}$ & $1.2-1.5$ & $1984-3078$ & $\mathrm{~T}_{27}-\mathrm{T}_{29}$ & Gas-bearing layers: $\mathrm{a}_{2}, \mathrm{a}_{4}, \mathrm{a}_{6}$ & Unused layers: $\mathrm{a}_{3}, \mathrm{a}_{5}, \mathrm{a}_{7}$ \\
$\mathrm{~b}_{1}-\mathrm{b}_{11}$ & $1.8-2.0$ & $1874-3047$ & $\mathrm{~T}_{29}-\mathrm{T}_{30}$ & Potential gas-bearing: $\mathrm{b}_{5}, \mathrm{~b}_{7}, \mathrm{~b}_{9}$ & Unused layers: $\mathrm{b}_{2}, \mathrm{~b}_{4}, \mathrm{~b}_{6}, \mathrm{~b}_{8}, \mathrm{~b}_{10}$ \\
$\mathrm{c}_{1}-\mathrm{c}_{11}$ & $2.1-2.4$ & $1923-3015$ & $\mathrm{~T}_{30}-\mathrm{T}_{40}$ & Potential gas-bearing: $\mathrm{c}_{3}, \mathrm{c}_{5}, \mathrm{c}_{7}$ & Unused layers: $\mathrm{c}_{2}, \mathrm{c}_{4}, \mathrm{c}_{6}, \mathrm{c}_{8}$ \\
\hline
\end{tabular}

Based on the DIVA interpretation sections of both the shallow and middle-deep strata, it can be clearly demonstrated that the class I abnormal DIVA zones are normally in the shallow strata, whereas the class II abnormal DIVA zones are usually in the middle-deep strata.

Fig. 7 shows two class I abnormal DIVA zones located on CDPs of 2,000-2,200 and 2,630-2,900, separated by one class II abnormal DIVA zone in-between.

In the middle-deep strata a strong abnormal DIVA zone is shown, but their classes are lower than those in the shallow strata. Fig. 8 shows a class II and a class III abnormal DIVA zones. Fig. 9 shows two class II abnormal DIVA zones. One occurs at the depth about $\mathrm{T}_{40}$, located on CDPs from 2,420 to 3,000 , deeper than the other with a depth around $\mathrm{T}_{30}-\mathrm{T}_{40}$, located on CDPs from 1,920 to 2,250. The former appears to be more obvious than the latter in terms of abnormal degrees.

The abnormal DIVA zones discussed above are closely related to the abnormal velocity distribution. The velocity of gas-bearing sandstones is normally lower than that of the surrounding rocks displaying primarily class I DIVA 



Fig. 7 a: Distribution of $a_{1}-a_{10}$ interpreted layers on the seismic section. b: DIVA interpretation section in the shallow strata (a segment), DF1-1 Gas Field. Solid lines represent the shallow velocity, and dashed lines represent the deep velocity

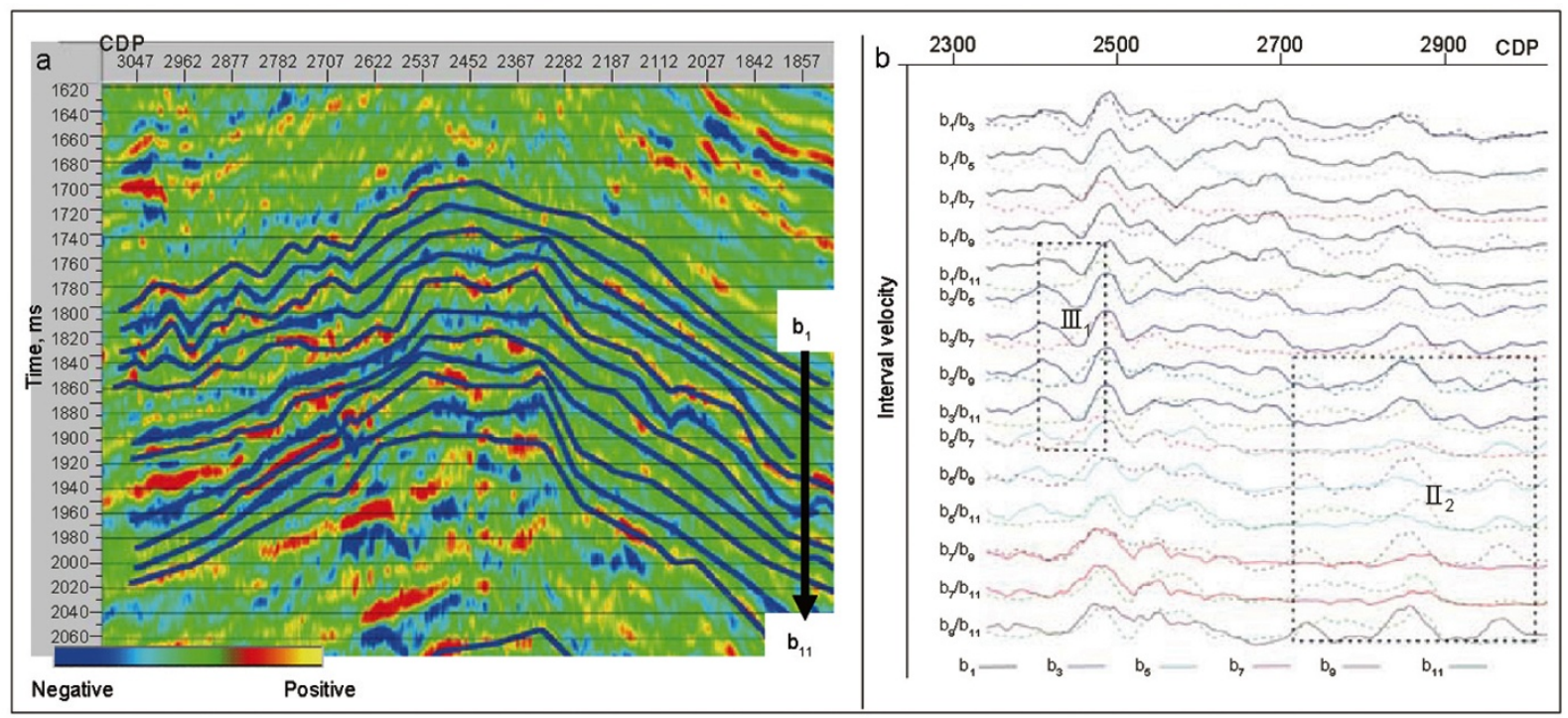

Fig. 8 a: Distribution of $b_{1}-b_{11}$ interpreted layers on seismic section. b: DIVA interpretation section for the middle strata (b segment), DF1-1 Gas Field. Solid lines mark the shallow velocity, and dashed lines mark the deep velocity
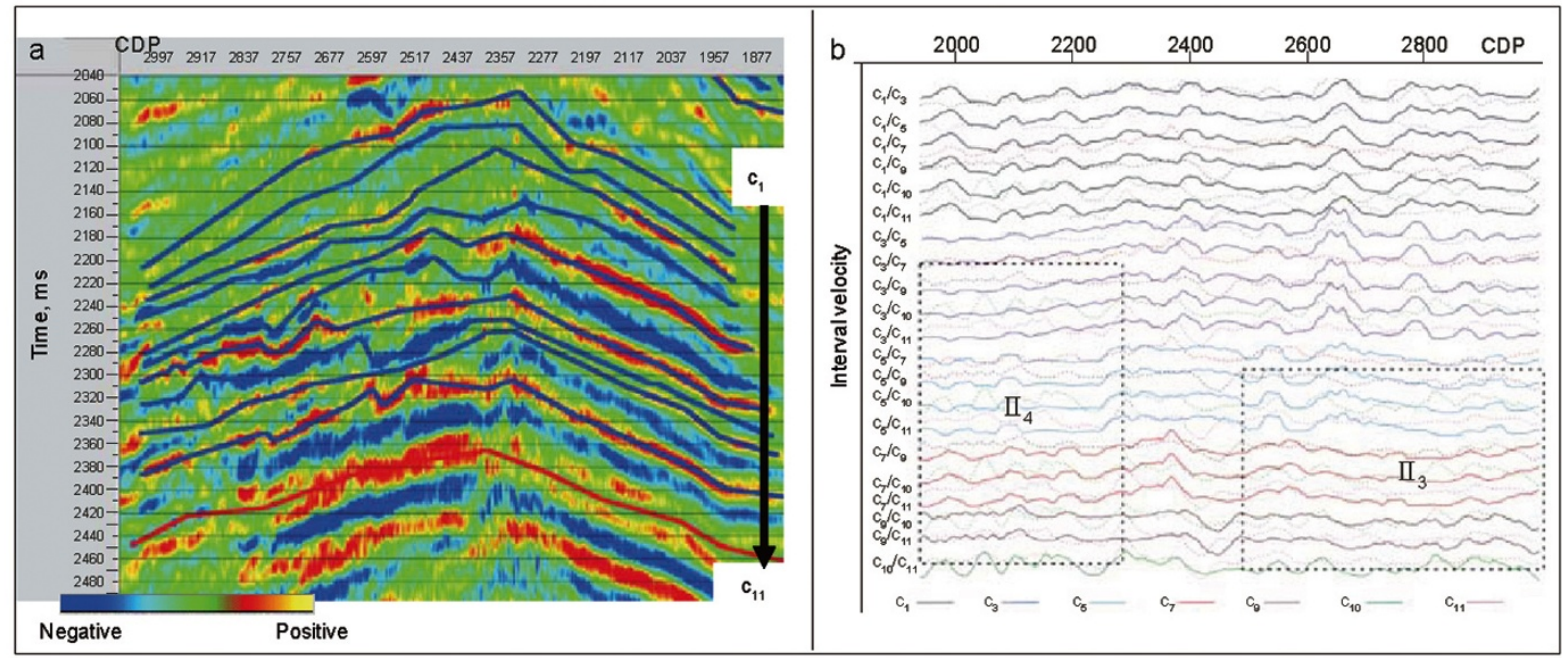

Fig. 9 a: Distribution of $c_{1}-c_{11}$ interpreted layers on seismic section. b: DIVA interpretation section in deep strata (c segment), DF1-1 Gas Field. Solid lines mark the shallow velocity, and dashed lines mark the deep velocity 
characteristics in the corresponding zones in the shallow strata. In the middle-deep strata, the class I abnormally changes into class II as shown on the DIVA sections because of the reduction of the velocity declination degree in the gasbearing layers, showing velocity reversal and poor seismic quality.

\section{Conclusions}

Velocity analyses from well logs and seismic data of the DF1-1 Gas Field in the Yinggehai Basin, South China Sea indicate that the velocity-depth trend is linear excluding the gas-bearing sandstones until the depth of 2,100 m $(2.25$ s TWT) in the shallow strata. The slope of the trend line indicates a higher velocity-depth gradient in the shallow strata compared with published data elsewhere. In contrast in the middle-deep strata below 2,100 m (2.25 s TWT), the velocitydepth relationship does not show a normal linear trend, but exhibits distinct velocity reversal. The velocity between the gas-bearing sandstones and the surrounding rocks also exhibits distinct variations in the shallow strata, but becomes indistinguishable in the middle-deep strata. The velocity reversal is believed to be mainly caused by high temperature and abnormally high pressure as the velocity anomaly and pressure anomaly occur at the same depth.

The DIVA method has been found to be an effective DHI both in the shallow and the middle-deep strata in the study area. Two DIVA DHI anomalies have been identified on the seismic profiles with class I abnormal DIVA zones associated with the shallow strata, and class II abnormal DIVA zones associated with the middle-deep strata.

\section{Acknowledgements}

This study was supported by the National Natural Science Foundation of China (No.40702024) and partly funded by AAPG Grant-in-Aid to the first author. Also, the Project was sponsored by the Scientific Research Foundation for the Returned Overseas Chinese Scholars, Ministry of Education of China (No.2009022014) and Open Research Foundation of Key Laboratory of Tectonics and Petroleum Resources (China University of Geosciences), Ministry of Education (No.TPR2009-33). The authors would like to thank the Zhanjiang Branch of CNOOC for providing well and seismic data.

\section{References}

Cook E E, Neidell N S and Beard J H. Precision measurements of interval velocity differences from seismic data. AAPG Annual Convention. 1983. 67(3): 442

Hansen S. Quantification of net uplift and erosion on the Norwegian Shelf south of 66 degrees $\mathrm{N}$ from sonic transit times of shale. Norsk Geologisk Tidsskrift. 1996. 76: 245-252

Hao F, Li S T, Gong Z S, et al. Thermal regime, inter-reservoir compositional heterogeneities, and reservoir-filling history of the Dongfang Gas Field, Yinggehai Basin, South China Sea: Evidence for episodic fluid injections in overpressured basins. AAPG Bulletin. 2000. 84(5): 607-626
He L, Xiong L and Wang J. Heat flow and thermal modeling of the Yinggehai Basin, South China Sea. Tectonophysics. 2002. 351(3): 245-253

Hermanrud C, Wensaas L, Teige G M G, et al. Shale porosities from well logs on Haltenbanken (offshore mid-Norway) show no influence of overpressuring. In: Law B E, Ulmishek G F and Slavin V I (Eds.), Abnormal pressures in hydrocarbon environments. AAPG Memoir. 1998. 70: $65-85$

Huang B J, Xiao X M and Li X X. Geochemistry and origins of natural gases in the Yinggehai and Qiongdongnan basins, offshore South China Sea. Organic Geochemistry. 2003. 34(7): 1009-1025

Huang B J, Xiao X M, Hu Z L, et al. Geochemistry and episodic accumulation of natural gases from the Ledong Gas Field in the Yinggehai Basin, offshore South China Sea. Organic Geochemistry. 2005. 36(12): 1689-1702

Japsen P. Velocity-depth trends in Mesozoic and Cenozoic sediments from the Norwegian Shelf: Discussion. AAPG Bulletin. 2006. 90(7): 1141-1143

Li X X. Seismic recognition techniques of shallow gas reservoirs in the Yinggehai Basin. China Offshore Oil and Gas. 2000. 14(3): 193-199 (in Chinese)

Loizou N, Liu E and Chapman M. AVO analyses and spectral decomposition of seismic data from four wells west of Shetland, UK. Petroleum Geoscience. 2008. 14(4): 355-368

Storvoll V and Bjørlykke K. Sonic velocity and grain contact properties in reservoir sandstones. Petroleum Geoscience. 2004. 10(3): 215-226

Storvoll V, Bjørlykke K and Mondol N H. Velocity-depth trends in Mesozoic and Cenozoic sediments from the Norwegian Shelf. AAPG Bulletin. 2005. 89(3): 359-381

Teige G M G, Hermanrud C, Wensaas L, et al. The lack of relationship between overpressure and porosity in North Sea and Haltenbanken shales: Overpressure research. Marine and Petroleum Geology. 1999. 16(4): 321-335

Xia B, Zhang Y, Cui X J, et al. Understanding of the geological and geodynamic controls on the formation of the South China Sea: A numerical modelling approach. Journal of Geodynamics. 2006. 42(1/3): 63-84

Yan Y, Hu X Q, Lin G, et al. Denudation history of South China block and sediment supply to northern margin of the South China Sea. Earth Science-Journal of China University of Geosciences. 2009. 20(1): 57-65

Yin P, Berne S, Vagner P, et al. Mud volcanoes at the shelf margin of the East China Sea. Marine Geology. 2003. 194(3/4): 135-149

Young K T and Tatham R H. Fluid discrimination of poststack "bright spots" in the Columbus Basin, offshore Trinidad. The Leading Edge. 2007. 26(12): 1508-1515

Yuan S Q, Yao G S, Lü F L, et al. Features of late Cenozoic deepwater sedimentation in southern Qiongdongnan Basin, northwestern South China Sea. Earth Science-Journal of China University of Geosciences. 2009. 20(1): 172-179

Zhang Y F, Sun Z, Zhou D, et al. Stretching characteristics and its dynamic significance of the northern continental margin of South China Sea. Science in China Series D: Earth Sciences. 2008. 51(3): 422-430

Zhou D and Yao B C. Tectonics and sedimentary basins of the South China Sea: Challenges and progresses. Earth Science-Journal of China University of Geosciences. 2009. 20(1): 1-12

Zhu H T, Chen K Y and Zhu P M. Application of DIVA technique in Yinggehai Basin. Oil Geophysical Prospecting. 2004. 39(3): 319321 (in Chinese)

(Edited by Hao Jie) 